\title{
European Society of Clinical Microbiology and Infectious Diseases \\ International Society for Anaerobic Bacteria \\ FOURTH EUROPEAN CONGRESS \\ and \\ SECOND INTERNATIONAL SYMPOSIUM \\ on \\ ANAEROBIC BACTERIA AND INFECTIONS \\ will be held at the \\ Hofburg Conference Centre, Vienna, Austria on March 8-11, 1992
}

Preliminary programme (keynote speakers):

Monday, March 9: $\quad$ Virulence (Tor Hofstad); Pathogenesis (Ori Rotstein); General microflora (Cyril Tancrede); Epidemiology (Soad Tabaqchali).

Tuesday, March 10: $\quad$ Genetics (Abigail Salyers); New Methods (Andrew Onderdonk); Antimicrobial resistance (Peter Appelbaum).

Wednesday, March 11: Clinical infections (Sidney Finegold).

Further information from: E.S.C.M.I.D. "Anaerobic Congress",

P.O. Box 330347 ,

D-8000 Munich 33,

Germany.

Tel: $089 / 6126162$

Fax: $089 / 6128176$ 